\title{
The Ability of ICU Admission to Detect Maternal Near Misses as Defined By The Who Near-Miss Criteria
}

\author{
Bower $\mathrm{G}^{\mathrm{a}}$, Dias $\mathrm{T}^{\mathrm{b}, c}$, Shanmugaraja $\mathrm{V}^{\mathrm{b}}$, Lee $\mathrm{M}^{\mathrm{a}}$, Cooper $\mathrm{D}^{\mathrm{a}}$, Crofton $\mathrm{H}^{\mathrm{a}}$, Kumarasiri $\mathrm{S}^{\mathrm{b}}$, Padeniya $\mathrm{T}^{\mathrm{b}}$
}

\begin{abstract}
Objective: to assess the ability of intensive care unit (ICU) admission in pregnancy, or the postpartum period, to detect cases of obstetric near-miss.
\end{abstract}

Methods: All obstetric admissions to the ICU were included retrospectively and data collected as specified by 2011 World Health Organization (WHO) guidelines on evaluating obstetrics near-misses between 2010 and 2013 in a Sri Lankan Hospital. Proportion of ICU admissions which fulfilled the WHO criteria for Severe Acute Maternal Morbidity (SAMM), maternal mortality ratio (MMR), maternal near-miss mortality ratio (MNM: MM)), and maternal near-miss ratio (MNMR) were analysed.

Results: A total of 9,608 live births were reported. $118 \mathrm{ICU}$ admissions and four maternal deaths were analysed. MMR was 42 per 100,000. MNMR was 9.7 per 1000, and MNM: MM was 23:1. From all ICU admissions 99 cases (79.8\%) met additional WHO near-miss criteria and were classified as true SAMM. Pregnancy-induced hypertensive disorders accounted for majority of ICU admissions (37.7\%). Out of eight published studies from our region non of them had a MNM: MM higher than ours.

Conclusions: Obstetric near-misses may be over-diagnosed if ICU admission is considered an independent inclusion criterion for SAMM. Reporting the proportion of patients admitted to ICU which are true near-miss may illustrate differing admission thresholds for a given institution.

Keywords: WHO near miss approach, obstetric near-miss, severe acute maternal mortality, maternal near-miss mortality ratio

\section{INTRODUCTION}

The maternal mortality ratio (MMR) is one of the most widely reported health indices and is commonly used to assess the quality of maternal health and obstetric practice within healthcare settings. However, in many

a St George's University of London, United Kingdom

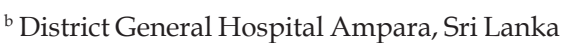

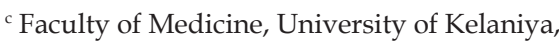
Sri Lanka

Correspondence: Dr.Tiran Dias MBBS MD MRCOG (UK) MD (London) Dip (Fetal Med) UK Senior Lecturer in Obstetrics and Gynaecology Consultant Obstetrician and Gynecologist Accredited Fetal Medicine Specialist North Colombo Teaching Hospital Ragama Sri Lanka

Telephone: +94 -112961000/112958219

Fax: +94-112958337

E-mail: thiran_dias@yahoo.com

Competing interests: None parts of the world maternal death is an increasingly rare event. Consequently the total numbers of maternal deaths used to calculate the MMR are often small, resulting in large standard errors $^{1}$. This is especially true when the total population being studied is small, such as local regions, individual institutions, or for population data taken over relatively short periods of time ${ }^{2}$. This places significant restriction on the conclusions which can be drawn from MMR, and it is now being recognised that even in settings with a relatively high rate of maternal deaths, the ratio performs poorly as a health index ${ }^{3}$. It is within this context that methods to monitor rates of severe acute maternal morbidity (SAMM) has been developed.

Review of data on the epidemiology of SAMM and maternal mortality may be a more useful guide to the improvement of obstetric services than maternal mortality data alone ${ }^{4}$, particularly within the contest of individual institutions and regions. They also allow analysis of the factors which contributed to survival in a nearmiss case, rather than concentrating factors causing death alone $\mathrm{s}^{5}$. Common MNM statistics are shown in Table 1. There has been a wide variety of definitions for MNM and SAMM ${ }^{2}$. Inclusion criteria in different studies have ranged from using interventions, such as emergency obstetric hysterectomy or ICU admission, to using definitions of disease entities or organ dysfunction. Defining SAMM by critical intervention, such as emergency hysterectomy or blood transfusion has also been used ${ }^{6,7}$. To counter this, organ dysfunction classifications have been used to highlight severe pregnancy related complications, regardless of the disease entity ${ }^{8}$. The most widely used of these in the context of SAMM is the Mantel criteria ${ }^{8}$. However, in lower resource settings the burden of recordkeeping required to fully assess organ function may be too much for poorly resourced institutions and lead to unreliable data capture ${ }^{9}$. Overall, the heterogeneity of definitions and inclusion criteria of SAMM have limited the power of comparisons between studies ${ }^{2}$.

In 2011 the WHO published guidelines on auditing MNM which aimed to offer standardised definitions for data collection methods with the aim of using near miss statistics in a similar way to $\mathrm{MMR}^{10}$. The working group defined near-miss as "a woman who nearly died but survived a complication that occurred during pregnancy, childbirth, or within 42 days of termination of pregnancy", and agreed a set of inclusion criteria that covered four major categories: severe maternal complications, critical interventions or intensive care unit use, life-threatening conditions and maternal vital status ${ }^{10}$ (Table 2). 
Sri Lanka has been exceptional in achieving WHO millennium development goals in maternal care ${ }^{11}$. The latest maternal mortality ratio (MMR) for Sri Lanka is 30 per 100 000 live births in year 2012 and MMR remained low compared to other South Asian countries ${ }^{11,12}$. Maternal mortality surveillance system adopted by the Family Health Bureau in Sri Lanka, with the help of Sri Lanka College of Obstetricians and Gynaecologists, has been instrumental for this success $^{11}$. However, with the recent decline in the number of maternal deaths, it has become apparent that maternal mortality reviews alone may not generate enough data to help further reduce maternal mortality ${ }^{4}$. Consequently, attempts to use MNM as a tool to assess the quality of obstetric care could be of great value in further reducing maternal mortality and improving maternal health. Our aim was to audit all obstetric admissions to ICU and to use the data to assess the ability of ICU admission to detect true near miss, as defined by the WHO criteria. We also wanted to compare our MNMR and MMR with other studies from the region to see whether a conclusion on our performance within the region could be reliably made from comparison of data.

\section{METHODS}

This was a retrospective descriptive study of all pregnancy-related admissions to ICU between August
2010 and May 2013 in District General Hospital Ampara Sri Lanka. Patient records of pregnancy-related admissions to ICU were searched from hospital archives by three doctors independently. All women admitted to ICU for complications relating to pregnancy and puerperium were included. All women were either directly admitted to ICU or admitted to ICU following an admission to the hospital. All maternal deaths during the study period were included regardless of whether they were admitted to ICU or not. Details of maternal deaths were cross-checked with national data. The prevalence of SAMM is generally expected to be around 7.5 cases/1000 deliveries and WHO recommends a sample containing at least 20 cases of severe maternal outcomes for an audit ${ }^{10}$.

The maternal near-miss mortality ratio was calculated (MNM / MM). This ratio refers to the ratio between SAMM cases and maternal death. Higher ratios indicate better care ${ }^{10}$. Common terminology in maternal morbidity and mortality is given in Tables 1 \& 2. Data on patient demographics, disease entity, investigation results, interventions and organ dysfunction as set out by the WHO near-miss criteria were entered on to a purpose built MS/Excel sheet ${ }^{10}$. Indication for admission to ICU was recorded in order to determine the disease entities responsible for ICU admission which were not part of the WHO disease entity criteria. Some additions to the WHO criteria were included to reflect local circumstances and help to assess the quality of management: use of uterine tamponade and magnesium sulphate were added to our intervention criteria, as these are common interventions used at our centre for managing $\mathrm{PPH}$ and severe pre-eclampsia respectively. Ethical approval was obtained from the Ampara District Hospital's ethical committee and each case was identified by patient record number alone, ensuring anonymity.

A literature review of all studies into obstetric near-miss in the south Asian region was performed. We used the search terms set out by a recent systematic review of all studies into SAMM $^{2}$. We defined south Asian region as: Pakistan, India, Sri Lanka, Bangladesh, Afghanistan, Nepal, Malaysia, Indonesia and Singapore. We have excluded studies outside these regions. We excluded studies published before 2004 to ensure the data was up to date. We also excluded studies which used emergency hysterectomy alone as their inclusion criteria, as results from these studies inevitably dealt with a much narrower definition of SAMM than our own. To compare the maternal mortality and the maternal near miss rates of our study with that of the region, published data on other countries was used. A power calculation was performed for comparison with each study in order to identify the comparisons that are adequately powered $(>80 \%)$ at an alpha error of $5 \%$.

\section{Table 1: Common maternal near miss statistics ${ }^{10}$}

Maternal near-miss (MNM) refers to a woman who nearly died but survived a complication that occurred during pregnancy, childbirth or within 42 days of termination of pregnancy.

Maternal death (MD) is the death of a woman while pregnant or within 42 days of termination of pregnancy or its management, but not from accidental or incidental causes.

MNM ratio (MNMR) refers to the number of maternal near-miss cases per 1000 live births (MNMR = MNM/LB). Similarly to the SMOR, this indicator gives an estimation of the amount of care and resources that would be needed in an area or facility.

Maternal near-miss maternal mortality ratio (MNM:MM) refers to the number of near misses for the number of maternal deaths. 
Table 2: WHO near miss inclusion criteria ${ }^{10}$

\begin{tabular}{|c|c|}
\hline $\begin{array}{l}\text { Severe maternal complications } \\
\text { Severe postpartum haemorrhage } \\
\text { Severe pre-eclampsia } \\
\text { Eclampsia } \\
\text { Sepsis or severe systemic infection } \\
\text { Ruptured uterus } \\
\text { Severe complications of abortion } \\
\text { Critical interventions or intensive care unit use } \\
\text { Admission to intensive care unit } \\
\text { Interventional radiology } \\
\text { Laparotomy (includes hysterectomy, excludes caesarean section) } \\
\text { Use of blood products } \\
\text { - Acute cyanosis, gasping, severe tachypnea (respiratory rate }>40 \\
\text { breaths per minute), severe bradypnea (respiratory rate }<6 \text { breaths } \\
\text { per minute), intubation and ventilation not related to anaesthesia, } \\
\text { severe hypoxemia (O2 saturation }<90 \\
\text { loss of consciousness), use of continuous vasoactive drugs, } \\
\text { cardiopulmonary resuscitation, severe hypoperfusion (lactate }>5 \\
\text { mmol/l or }>45 \text { mg/dl), severe acidosis (pH }<7.1 \text { ) } \\
\text { Respiratory dysfunction }\end{array}$ & $\begin{array}{l}\text { - Renal dysfunction } \\
\text { - Oliguria non-responsive to fluids or diuretics, dialysis for } \\
\text { acute renal failure, severe acute azotemia (creatinine } 300 \\
f \text { Êmol/ml or } .3 .5 \mathrm{mg} / \mathrm{dl} \text { ) } \\
\text { - Coagulation/haematological dysfunction } \\
\text { - Failure to form clots, massive transfusion of blood or red cells } \\
\text { (>5 units),severe acute thrombocytopenia ( }<50000 \text { platelets/ } \\
\text { ml) } \\
\text { - Hepatic dysfunction } \\
\text { - Jaundice in the presence of pre-eclampsia, severe acute } \\
\text { hyperbilirubinemia (bilirubin }>100 f \text { Êmol/l or }>6.0 \text { mg/dl) } \\
\text { - Neurological dysfunction } \\
\text { - Prolonged unconsciousness (lasting .12 hours)/coma } \\
\text { (including metabolic coma), stroke, uncontrollable fits/status } \\
\text { epilepticus, total paralysis } \\
\text { - Uterine dysfunction } \\
\text { - Uterine haemorrhage or infection leading to hysterectomy }\end{array}$ \\
\hline
\end{tabular}

\section{RESULTS}

A total of 9,608 live births and four maternal deaths. were reported during the study period here were 124 pregnancy-related admissions to ICU (1.29\% of all deliveries) including the four maternal deaths. Women who delivered elsewhere and transferred only for ICU care were excluded. Case notes of 118 ICU admissions were analysed. Two sets of notes could not be traced. The maternal mortality ratio of our institution was 42 per 100,000. One death was due to septic abortion, one from seizure disorder aggravated during pregnancy, one from heart failure complicated by combination of post-partum haemorrhage and sepsis, and one from electrolyte imbalance secondary to severe hyperemesis gravidarum. Ninety nine patients $(80 \%)$ met one of the WHO near-miss criteria other than ICU admission and were classed as trueSAMM. 25 patients
Table 3: Demographics of study population

\begin{tabular}{|c|c|}
\hline Mean age (range) years & $28.7(17-44)$ \\
\hline Mean gestational age at admission (Range) weeks & $32(4-40)$ \\
\hline \multicolumn{2}{|l|}{ Parity } \\
\hline - Primipara (\%) & $54(44.3)$ \\
\hline - Multi (\%) & $68(55.7)$ \\
\hline Term pregnancies $-\geq 37$ weeks $(\%)$ & $57(46.7)$ \\
\hline Pre-term pregnancies - 24-36 weeks (\%) & $47(38.5)$ \\
\hline Miscarriage $-<24$ weeks (\%) & $15(12.3)$ \\
\hline Post-partum at presentation (\%) & $4(3.3)$ \\
\hline Maternal deaths & 4 \\
\hline Maternal mortality ratio (per 100,000 ) & 42 \\
\hline
\end{tabular}


(20\%) met no additional criteria and so were not considered true SAMM. The maternal near-miss rate was 9.7 per 1000 and the maternal near-miss maternal mortality ratio (MNM:MM) was 23:1. The demography of the study population is shown in Table 3. The maternal near-misses according to WHO criteria are shown in Table 4.

The commonest reasons for ICU admission were pregnancyinduced hypertensive disorders; $\mathrm{PIH}$, severe pre-eclampsia and eclampsia accounted to $37.7 \%$ of all ICU admissions. All patients with severe pre-eclampsia and eclampsia received magnesium sulphate bolus and infusion. Severe post-partum haemorrhage was the second leading cause of ICU admission (19.7\%). All but one patient with PPH required blood transfusion and nine patients required transfusion of five or more units of blood products. Eight of these patients $(33.3 \%)$ had a hysterectomy to control bleeding. Uterine condom catheter tamponade was performed in 11 of cases of PPH (45.8\%), and of those patients only one went on to have a hysterectomy. Sepsis (13.1\%) was the third most common reasons for admission to ICU. All the patients with sepsis received intravenous antibiotics.

A total of 44 patients (36\%) met the criteria for a single organ dysfunction, and 15 patients (12\%) had multiple organ dysfunction. Cardiovascular, respiratory and coagulation dysfunction were the commonest types of organ dysfunction. Of the 25 $(20 \%)$ patients who did not meet other WHO inclusion criteria 11 patients were admitted for cardiac disease and cardiac monitoring, six patients for pre-eclampsia not considered severe enough to meet the WHO disease entity criteria, two patients for epilepsy, three for observation following general anaesthesia, one for thyrotoxicosis, one for severe hyperemesis gravidarum, and one for severe asthma exacerbation.

Literature review found seven studies into SAMM in the south Asian region (Table 5). No study had a MNM:MM higher than ours, while three studies had a MNMR lower than ours, although this was not statistically

Table 4: Maternal near miss at Ampara General Hospital (WHO criteria)

\begin{tabular}{|c|c|c|}
\hline & Number & Percentage \\
\hline \multicolumn{3}{|l|}{ Critical interventions: } \\
\hline ICU admissions for obstetric complications & 122 & 100 \\
\hline Use of blood products & 50 & $41.00 \%$ \\
\hline Massive transfusion ( $\geq 5$ units $\mathrm{RBC}$ ) & 11 & $9.00 \%$ \\
\hline Emergency surgery (excluding C-section) & 20 & $16.40 \%$ \\
\hline Uterine tamponade & 11 & $9.00 \%$ \\
\hline Interventional radiology & - & - \\
\hline $\mathrm{MgSO}_{4}$ & 35 & $28.70 \%$ \\
\hline \multicolumn{3}{|l|}{ Life-threatening conditions: 75 (61.98\%) } \\
\hline $\mathrm{PPH}$ & 24 & $19.83 \%$ \\
\hline Severe pre-eclampsia & 28 & $23.14 \%$ \\
\hline Eclampsia & 7 & $5.78 \%$ \\
\hline Sepsis or SIRS & 16 & $13.23 \%$ \\
\hline Ruptured uterus & 0 & $0.00 \%$ \\
\hline \multicolumn{3}{|c|}{ Other conditions with ICU admission: 46 (38.02\%) } \\
\hline Abortion / miscarriage & 6 & $4.96 \%$ \\
\hline Ectopic pregnancy & 4 & $3.31 \%$ \\
\hline Pregnancy induced hypertension & 11 & $9.09 \%$ \\
\hline Cardiovascular disease & 15 & $12.39 \%$ \\
\hline Respiratory disease & 4 & $3.31 \%$ \\
\hline Placental abruption / praevia & 3 & $2.48 \%$ \\
\hline Hyperemesis gravidarum & 2 & $1.65 \%$ \\
\hline Epilepsy & 1 & $0.83 \%$ \\
\hline Organ dysfunction: & 44 & $36.10 \%$ \\
\hline Cardiovascular & 19 & $15.60 \%$ \\
\hline Respiratory & 17 & $14.00 \%$ \\
\hline Renal & 3 & $2.50 \%$ \\
\hline Coagulation & 14 & $11.50 \%$ \\
\hline Hepatic & 1 & $0.80 \%$ \\
\hline Neurological & 5 & $4.10 \%$ \\
\hline Uterine & 12 & $9.80 \%$ \\
\hline Multi-organ failure & 15 & $12.30 \%$ \\
\hline
\end{tabular}

significant. Three other studies looked at ICU admissions only. Comparisons of our MMR rates with studies by Ranathunga et al. and Karnad et al. were not powered enough for comparison $^{13,14}$. All other studies were suitable for comparison and MMR was significantly lower in our study than when compared to the regional data $^{13-20}$. Results from the literature review are shown in Table 5. 
Table 5: Literature review of MNM from South Asian Region

\begin{tabular}{|c|c|c|c|c|c|c|c|c|c|}
\hline & $\begin{array}{l}\text { Bangladesh } \\
\text { Huda } 2012\end{array}$ & $\begin{array}{l}\text { India } \\
\text { Karnad } \\
2004\end{array}$ & $\begin{array}{c}\text { Indonesia } \\
\text { Adisasmita } \\
2008\end{array}$ & $\begin{array}{c}\text { Indonesia } \\
\text { Ronsmans } \\
2008\end{array}$ & $\begin{array}{c}\text { Nepal } \\
\text { Srestha } \\
2010\end{array}$ & $\begin{array}{l}\text { Pakistan } \\
\text { Bibi } 2008\end{array}$ & $\begin{array}{c}\text { Pakistan } \\
\text { Mustafa } \\
2009\end{array}$ & $\begin{array}{c}\text { Sri Lanka } \\
\text { Ranatunga } \\
2012\end{array}$ & Our study \\
\hline $\begin{array}{l}\text { Inclusion } \\
\text { criteria }\end{array}$ & $\begin{array}{l}\text { Ronsmans et } \\
\text { al., } 2009 \text { cited }\end{array}$ & $\begin{array}{c}\text { ICU } \\
\text { admission }\end{array}$ & $\begin{array}{l}\text { Mantel } \\
\text { (adapted) }\end{array}$ & $\begin{array}{c}\text { Mantel } \\
\text { (adapted) }\end{array}$ & $\begin{array}{l}\text { Geller et } \\
\text { al., } 2004 \\
\text { cited }\end{array}$ & $\begin{array}{c}\text { ICU } \\
\text { admission }\end{array}$ & $\begin{array}{c}\text { Mantel } \\
\text { (modified) }\end{array}$ & $\begin{array}{c}\text { ICU } \\
\text { admission } \\
+ \text { WHO }\end{array}$ & $\begin{array}{c}\text { ICU } \\
\text { admission } \\
+\mathrm{WHO}\end{array}$ \\
\hline $\begin{array}{l}\text { MMR (per } \\
100,000)\end{array}$ & 255 & 119 & 1130 & 95 & 324 & 450 & 792 & 30 & 42 \\
\hline MNMR (per 1000) & 67 & 5.5 & 135 & 6 & 23 & 13.5 & 50.6 & 5.5 & 9.7 \\
\hline MNM:MM ratio & 12 & 5 & 12 & 15 & 7 & 3 & 7 & 18 & 23 \\
\hline $\begin{array}{l}\text { ICU admissions } \\
\text { (\% total } \\
\text { deliveries) }\end{array}$ & $n / a$ & 0.59 & 0.67 & $n / a$ & 1.79 & 1.35 & $\mathrm{n} / \mathrm{a}$ & 1.56 & 1.29 \\
\hline \multicolumn{10}{|l|}{ Disease criteria } \\
\hline PPH (\%) & $\mathrm{n} / \mathrm{a}$ & 14.0 & 26.3 & 15.8 & 8.3 & 13 & 21.3 & 36.3 & 19.7 \\
\hline $\begin{array}{l}\text { Severe } \\
\text { preeclampsia (\%) }\end{array}$ & $\mathrm{n} / \mathrm{a}$ & 31.1 & 9.6 & 2.7 & 13.9 & 20 & 6.3 & 13.2 & 23 \\
\hline Eclampsia (\%) & $\mathrm{n} / \mathrm{a}$ & 14.0 & 13.0 & 8.5 & 13.9 & 33 & 2.1 & 6.6 & 5.7 \\
\hline Sepsis / SIRS (\%) & $\mathrm{n} / \mathrm{a}$ & 6.2 & 0.1 & 1.4 & 19.4 & 17.00 & 4.2 & 3.3 & 13.1 \\
\hline $\begin{array}{l}\text { Uterine rupture } \\
(\%)\end{array}$ & $\mathrm{n} / \mathrm{a}$ & 0.4 & 3.4 & 3.3 & 2.8 & 3.00 & 4.2 & 2.2 & 0 \\
\hline $\begin{array}{l}\text { Miscarriage / } \\
\text { abortion (\%) }\end{array}$ & $\mathrm{n} / \mathrm{a}$ & - & 13.1 & 7.3 & 27.8 & - & - & 2.2 & 4.9 \\
\hline Ectopic (\%) & $\mathrm{n} / \mathrm{a}$ & 0.4 & 8.9 & 8.9 & 2.8 & - & 6.3 & - & 3.3 \\
\hline \multicolumn{10}{|l|}{$\begin{array}{l}\text { Critical } \\
\text { Intervention }\end{array}$} \\
\hline $\begin{array}{l}\text { ICU admission } \\
(\%)\end{array}$ & $\mathrm{n} / \mathrm{a}$ & 100.0 & 5.0 & - & 77.8 & 100 & - & 100.0 & 100.0 \\
\hline $\begin{array}{l}\text { Use of blood } \\
\text { products (\%) }\end{array}$ & $\mathrm{n} / \mathrm{a}$ & 38.2 & - & - & 66.7 & 40 & - & 43.9 & 41 \\
\hline $\begin{array}{l}\text { Emergency } \\
\text { surgery (\%) }\end{array}$ & $\mathrm{n} / \mathrm{a}$ & 23.0 & $2.5 \%$ & - & 16.7 & 14 & - & 24.8 & 16.4 \\
\hline $\begin{array}{l}\text { Interventional } \\
\text { radiology (\%) }\end{array}$ & $\mathrm{n} / \mathrm{a}$ & - & - & - & - & - & - & - & - \\
\hline \multicolumn{10}{|l|}{$\begin{array}{l}\text { Organ } \\
\text { Dysfunction }\end{array}$} \\
\hline $\begin{array}{l}\text { Cardiovascular } \\
(\%)\end{array}$ & $n / a$ & 4.4 & 77.7 & - & 38.9 & 40 & 4.2 & 9.9 & 15.6 \\
\hline Respiratory (\%) & $\mathrm{n} / \mathrm{a}$ & 22.0 & 0.1 & - & - & 53 & - & 1.1 & 14 \\
\hline Renal (\%) & $\mathrm{n} / \mathrm{a}$ & 35.5 & 4.5 & - & 13.9 & - & 2.1 & 2.2 & 2.5 \\
\hline Coagulation (\%) & $\mathrm{n} / \mathrm{a}$ & 12.0 & 1.0 & - & 22.2 & - & 6.3 & 19.8 & 11.5 \\
\hline Hepatic (\%) & $\mathrm{n} / \mathrm{a}$ & 11.0 & 2.5 & - & 13.9 & - & - & 5.5 & 0.8 \\
\hline Neurological (\%) & $\mathrm{n} / \mathrm{a}$ & 28.3 & 1.8 & - & - & 3 & 4.2 & 1.1 & 4.1 \\
\hline Uterine (\%) & $\mathrm{n} / \mathrm{a}$ & 4.6 & 2.5 & - & - & 14 & - & 8.8 & 9.8 \\
\hline Multi-organ (\%) & $\mathrm{n} / \mathrm{a}$ & - & 22.7 & - & - & - & - & - & 12.3 \\
\hline
\end{tabular}




\section{DISCUSSION}

District general hospital Ampara is a tertiary level care centre for 700,000 people in eastern Sri Lanka. There have been average of 3,200 live births a year, with only four maternal deaths since August 2010. Therefore, evaluation of both near-miss cases and maternal deaths should better highlight the strengths and weakness of care given to these patients than examining maternal mortality alone. Our hospital has access to all laboratory tests and modes of monitoring laid out in the WHO guideline, something which has proved problematic in some lowresource settings ${ }^{21}$. Overall, our data suggests we are performing well in obstetric care, both nationally and in relation to the south Asian region. Our MNMR (10.3 per 1000) stands towards the lower end of the global range of $0.6 \%$ to 14.98 reported in the most recent systematic review of $\mathrm{MNM}^{2}$. It has been recognised that high maternal near-miss mortality ratio (MNM:MM) with low maternal near miss ratio (MNM) indicates good quality obstetric care (WHO criteria). We have reported the highest MNM:MM ratio (23:1) and our MNMR was the third lowest in the region (Table 5). Our maternal mortality rate (42) was higher than the national average of 35 per 100,000 .

A single death would significantly alter the maternal mortality rate in the context of the relatively small numbers in this study (one less death would change the MMR to 31 per 100,000) illustrating the problems with using MMR in settings with small numbers of maternal death and vindicating the use of MNM data. However, statistical analysis of the regional data showed that the MMR provided a more robust comparison than SAMM figures. There was generally less reporting bias between studies on MMR than SAMM statistics. Despite adequate sample size of the studies, comparison of MNM statistics is clinically less useful because of presumed under or over reporting of maternal near misses. This is primarily due to the non-uniformity of classifications.

With regards to the ability of ICU admission to detect true MNM cases, our results suggest that ICU admission may lead to an over-reporting of MNM if it is considered an independent defining criterion of MNM. Overall, 25 cases in our study $(20 \%)$ met no other WHO inclusion criteria than ICU admission: they did not meet any of the WHO's disease entity criteria, had no organ dysfunction and required no serious intervention. The majority of these patients were admitted for heart disease, requiring cardiac monitoring, or for pre-eclampsia which did not meet the WHO criteria for severe preeclampsia and therefore inclusion under disease entity. As these figures suggest, not all obstetric admissions to ICU are necessarily true near misses. The other study from Sri Lanka, which looked at MNM as defined by the WHO criteria, found an even greater proportion of obstetric ICU admissions (65\%) which did not meet additional WHO criteria ${ }^{13}$. $43 \%$ had organ dysfunction, and only $36 \%$ in our study ${ }^{13}$.

Although using ICU admission as an independent inclusion criterion provides an easily auditable critical event, it is likely to over-diagnose the number of true SAMM ${ }^{9}$, even within a relatively low-resource setting such as our institution. This would not necessarily be an issue if all obstetric units had similar thresholds for admission to ICU. However, regional differences in admission policy and variable pressures on intensive care resources are likely to affect the types of cases admitted to ICU. Evidence for this may be seen in the different proportion of patients admitted to ICU which were true and false near-miss between our study and Ranatunga et al. ${ }^{13}$. Under-reporting is also likely to be an issue in our study, as we would have missed cases of MNM which were not admitted to ICU.

Despite this, the WHO criteria provide a validated approach to classify obstetric near miss in a variety of healthcare settings and provides a way forward for standardising MNM so that it may become a powerful statistical tool in appraising the standard of obstetric care. There may be an issue with over-reporting MNM if ICU admission is used as an independent defining criterion. One way to overcome this would be to use ICU as a screening tool for MNM, with exclusion of false MNM from subsequent analysis. Alternatively, simply displaying the proportion of pregnancy-related ICU admissions which met no other near-miss criteria could serve as a useful comparative guide to the admission thresholds in the studied healthcare settings. In this context, definition based ICU admission as independent inclusion criteria for MNM could be still justified as it would provide a straightforward way to identify the more severe SAMM cases, screen them for true near miss, while indicating any great differences in admission thresholds between study populations.

Acknowledgements: We would like to thank Professor Sir Sabaratnam Arulkumaran for his guidance for this study.

Disclosure of interests: None.

\section{REFERENCES}

1. AbouZahr C, Wardlaw T. Maternal mortality at the end of a decade: signs of progress? Bulletin of the World Health Organization. 2001;79(6):561-8.

2. Tunçalp O, Hindin MJ, Souza JP, Chou $D$, Say L. The prevalence of maternal near miss: a systematic review. British Journal of Obstetrics and Gynaecology. 2012 May;119(6):653-61.

3. Say L, Souza JP, Pattinson RC; WHO working group on Maternal Mortality and Morbidity classifications. Maternal near miss--towards a standard tool for monitoring quality of maternal health care. Best Practice \& Research Clinical Obstetrics \& Gynaecology. 2009 Jun;23(3):287-96.

4. Pattinson RC, Hall M. Near misses: a useful adjunct to maternal death enquiries. British Medical Bulletin. 2003;67:231-43.

5. Filippi V, Brugha R, Browne E, Gohou V, Bacci A, De Brouwere V, Sahel A, Goufodji S, Alihonou E, Ronsmans C. Obstetric audit in resource-poor settings: lessons from a multi-country project auditing 'near miss' obstetrical emergencies. Health Policy Plan. 2004 Jan;19(1):57-66.

6. Fatima M, Kasi PM, Baloch SN, Afghan AK. Experience of emergency peripartum hysterectomies at a tertiary care hospital 
in quetta, Pakistan. ISRN obstetrics and gynecology. 2011;2011:854202

7. Saxena SV, Bagga R, Jain V, Gopalan S. Emergency peripartum hysterectomy. International Journal of Gynecology \& Obstetrics. 2004 May;85(2):172-3.

8. Mantel GD, Buchmann $\mathrm{E}$, Rees $\mathrm{H}$, Pattinson RC. Severe acute maternal morbidity: a pilot study of a definition for a near-miss. British Journal of Obstetrics and Gynaecology. 1998 Sep;105(9):98590 .

9. Senanayake $H$, Dias $T$, Jayawardena A. Maternal mortality and morbidity: epidemiology of intensive care admissions in pregnancy. Best Practice \& Research Clinical Obstetrics \& Gynaecology. 2013 Dec;27(6):811-20.

10. World Health Organization, Department of Reproductive Health and Research. Evaluating the quality of care for severe pregnancy complications, The WHO near-miss approach for maternal health.

11. http://www.who.int/reproductivehealth/ publications/monitoring/9789241502221/ en/

12. Senanayake $H$, Goonewardene $M$, Ranatunga A, Hattotuwa R, Amarasekera $\mathrm{S}$, Amarasinghe I. Achieving Millennium Development Goals 4 and 5 in Sri Lanka. British Journal of Obstetrics and Gynaecology. 2011 Sep;118 Suppl 2:7887
13. Annual Health Bulletin 2012 Sri Lanka Medical Statistics Unit Ministry of Health. http://www.health.gov.Ik/en/publication/ AHB2012/Annual\%20Health\%20 Bulletin\%20-\%202012.pdf

14. Ranatunga GA, Akbar JF, Samarathunga S, Perera YAG, Kariyawasam L, Kumarasiri JM. 'Severe acute maternal morbidity in a tertiary care institution'. Sri Lanka Journal of Obstetrics and Gynaecology, 2012; 34: 135-143

15. Karnad DR, Lapsia V, Krishnan A, Salvi VS. Prognostic factors in obstetric patients admitted to an Indian intensive care unit. Critical Care Medicine, 2004 Jun; 32(6): 1294-9.

16. Adisasmita A, Deviany PE, Nandiaty $F$, Stanton C, Ronsmans C. 'Obstetric near miss and deaths in public and private hospitals in Indonesia'. BMC Pregnancy and Childbirth, 2008, 8: 10. DOI: 10.1186/1471-2393-8-10.

17. Huda FA, Ahmed A, Dasgupta SK, Jahan M, Ferdous J, Koblinsky M et al. 'Profile of Maternal and Foetal Complications during Labour and Delivery among Women Giving Birth in Hospitals in Matlab and Chandpur, Bangladesh'. Journal of Health, Population and Nutrition, 2012 Jun; 30(2): 131-142.
18. Bibi S, Memon A, Sheikh JM, Qureshi AH Severe acute maternal morbidity and intensive care in a public sector university hospital of Pakistan. Journal of Ayub Medical College Abbottabad, 2008 JanMar;20(1):109-12

19. Shrestha NS, Saha R, Karki C. Near miss maternal morbidity and maternal mortality at Kathmandu Medical College Teaching Hospital. Kathmandu University Medical Journal, 2010 Apr-Jun;8(30):222-6.

20. Mustafa R, Hashmi $H$. Near-miss obstetrical events and maternal deaths. Journal of College of Physicians \& Surgeons Pakistan, 2009 Dec; 19(12): 781-5

21. Ronsmans C, Scott S, Adisasmita A, Deviany $P$, Nandiaty F. Estimation of population-based incidence of pregnancy-related illness and mortality (PRIAM) in two districts in West Java, Indonesia. British Journal of Obstetrics and Gynaecology, 2009; 116: 82-90.

22. van den Akker T, Beltman J, Leyten J, Mwagomba B, Meguid T, Stekelenburg $\mathrm{J}$, van Roosmalen J. The WHO maternal near miss approach: consequences at Malawian District level. PLoS One. 2013;8(1):54805. 